\title{
Prevalence of pregnancy induced thyroid disorders, diabetes and hypertension in a tertiary care teaching hospital: an observational study
}

\author{
Gowthami Mummalaneni $^{1 *}$, Tamaraba Narasingarao1, Krishna Kumari Myneni²
}

\begin{abstract}
${ }^{1}$ Department of Obstetrics and Gynecology, Maharajah's Institute of Medical Sciences, Nellimarla, Vizianagaram, Andhra Pradesh, India

${ }^{2}$ Consultant in Obstetrics and Gynecology, Muvva Gopala Hospital, Vizianagaram, Andhra Pradesh, India
\end{abstract}

Received: 25 May 2019

Revised: 27 June 2019

Accepted: 07 July 2019

\section{*Correspondence:}

Dr. Gowthami Mummalaneni,

E-mail: mummalanenigowthami95@gmail.com

Copyright: ( ) the author(s), publisher and licensee Medip Academy. This is an open-access article distributed under the terms of the Creative Commons Attribution Non-Commercial License, which permits unrestricted non-commercial use, distribution, and reproduction in any medium, provided the original work is properly cited.

\begin{abstract}
Background: Pregnancy induced thyroid disorders, gestational diabetes mellitus (GDM) and gestational hypertension are common problems in women with gestational period. Published literate shows wide range of prevalence in pregnancy induced disorders in other states of India, and as of now the exact prevalence in our study population is not studied. Hence, there present study was aimed to know the prevalence of pregnancy induced disorders in pregnant women in South Indian population.

Methods: A total of 120 subjects were followed-up at the time of recruitment to entire gestational period. Standard guidelines were followed for the assessment of thyroid hormone levels, glucose tolerance test (OGTT) and blood pressure values at different intervals and positions. Apart from detailed clinical history has been taken and routine basic and obstetrical investigations were done.

Results: Prevalence of thyroid dysfunction (15.0\%), gestational diabetes mellitus (11.7\%) and gestational hypertension $(9.2 \%)$ was reported in the present study population. Subclinical hypothyroidism was highest prevalence amount thyroid disorders. Gestational diabetes subjects have mean blood glucose levels of $230.68 \pm 17.48 \mathrm{mg} / \mathrm{dL}$ with OGTT test. Gestational hypertensive patients had SBP of $152.4 \pm 10.8$ and DBP of $96.6 \pm 6.4$; pre-hypertensive subjects had SBP of $134.2 \pm 5.48$ and DBP of $6.8 \pm 4.6$ respectively.

Conclusions: Our study findings were slightly higher than normal prevalence's which are reported earlier by various authors. We suggested that early screening, diagnosis and treatment are warranted for the prevention of maternal and fetal complications in Indian population.
\end{abstract}

Keywords: Diabetes, Hypertension, Observational study, Pregnancy, Thyroid disorders

\section{INTRODUCTION}

Pregnancy induced thyroid disorders, diabetes and hypertension are the common endocrine and cardiovascular disorders seen maternally either in early and late period of pregnancy. Maternal thyroid dysfunction contributes many risk factors which includes increase thyroglobulin levels, renal excretion of iodine due to increased rate of glomerular filtration, alterations in thyroid hormone peripheral metabolism and modifications in iodine transfer to placenta. ${ }^{1}$ Iodine requirement increases by $50 \%$ during gestation period which can be compensate with synthesis and production of maternal thyroid hormones from gland and $10 \%$ increase in gland size is estimated. ${ }^{2}$ Pregnancy is a stress factor for thyroid gland which resulting in hypothyroidism with dietary iodine deficiency and very limited thyroidal reserve women. Early pregnancy 
induced thyroid dysfunction has been associated with maternal complications such as abortion, preterm labour, pre-eclampsia, eclampsia and the fetal complications are low birth weight, prematurity, still birth and perinatal death. ${ }^{3}$ Women has hypothyroidism in $1^{\text {st }}$ trimester of pregnancy is very harmful for brain development of fetus which leads to mental retardation, cretinism, physical growth and development impairment and most organ systems will be affected. Postnatal complications are impaired intellectual development, attention deficit and hyperactivity syndrome and respiratory distress syndrome. ${ }^{4}$

Incidence of gestational diabetes mellitus (GDM) varies globally from $2 \%$ to $14 \% .{ }^{5}$ Gestational diabetes can cause complications to mother as well as fetus. Maternal complications include pre-eclampsia, placental abruption, needing to induce labour. Fetal complications are premature birth, macrosomia, trauma during the birth, neonatal hypoglycaemia, perinatal death. , $^{6,7}$

Gestational hypertension also referred to as pregnancy induced hypertension (PIH) is a condition characterized by high blood pressure during pregnancy. Hypertension during pregnancy affects about 6-8\% of pregnant women. ${ }^{8}$ Gestational hypertension can lead to a serious condition called preeclampsia usually begins after 20 weeks of pregnancy and usually goes away after childbirth. Complications of preeclampsia may include fetal growth restriction, preterm birth, placental abruption, HELLP syndrome, eclampsia and cardiovascular diseases. $^{9-11}$

Preeclampsia develops only as a complication of pregnancy. Risk factors are history of preeclampsia, chronic hypertension, first pregnancy, maternal age (>30), obesity, multiple pregnancy, in-vitro fertilization and history of certain conditions such as migraines, type 1 or type 2 diabetes, kidney diseases. ${ }^{12-14}$

Therefore, this study was carried out in pregnant women with entire gestation period during who attended antenatal clinic of Department of Obstetrics and Gynecology, Maharaja Institute of Medical Sciences, Vijayanagaram, Andhra Pradesh to know the prevalence of pregnancy induced thyroid disorders, diabetes and hypertension.

\section{METHODS}

A prospective, observational study was conducted at Department of Obstetrics and Gynecology, Maharaja Institute of Medical Sciences, Vijayanagaram, Andhra Pradesh during the period of January 2018 to March 2019. The present study was approved by scientific committee as well as Institutional Ethics Committee and Informed consent was obtained from all of the study participants. Study was conducted according to the Declaration of Helsinki.
Study participants were recruited during their routine antenatal OPD visits during first trimester of pregnancy and followed-up entire gestational period (40 weeks) up to delivery. After confirmation of gestational age, a total of 150 subjects who are in first trimester were randomly selected and included for the study.

\section{Inclusion criterion}

- Primigravida pregnancy/multigravida pregnancies

- $\quad<24$ weeks of gestational age

- $\quad$ Singleton pregnancy.

\section{Exclusion criteria}

- $\quad>37$ weeks of gestational age

- Multifetal gestation

- Known case of chronic disorders (thyroid dysfunction, diabetes, hypertension and PCOS).

A detailed clinical history was obtained by using predesigned data collection sheet.

Clinical history regarding menstrual history, obstetric history, family history, personal and social history, symptoms of thyroid disorders, diabetes and hypertension was recorded. General examination was carried out during the OPD visits which includes body temperature, pulse rate, blood pressure, respiratory rate, per abdominal and per vaginal examination was also done and findings were recorded.

\section{Investigations}

Pregnancy was confirmed by ultrasonography and clinical assessment. Blood samples were collected once in every 3 months (last week of trimester) for assessing thyroid profile (TSH, FT3, FT4 levels); fasting blood glucose levels, OGTT were conducted for diagnosis of gestational diabetes; two different points and position blood pressure were measured for the diagnosis of gestational hypertension. Basic investigations including complete blood picture, blood grouping and Rh typing, serum creatinine, $\mathrm{HIV}$, $\mathrm{Hbs} \mathrm{Ag}$ and complete urine examination were done.

\section{Classification}

\section{Thyroid disorders}

American Thyroid Association (ATA) for the Diagnosis and Management of Thyroid Disease during Pregnancy and Postpartum guidelines was followed. ${ }^{3}$

The normal references for TSH ranges according to ATA are:

First trimester -0.1 to $2.5 \mathrm{mIU} / \mathrm{L}$ Second trimester -0.2 to $3.0 \mathrm{mIU} / \mathrm{L}$ 
Third trimester -0.3 to $3.0 \mathrm{mIU} / \mathrm{L}$

Normal free T4 level is 0.7 to $1.8 \mathrm{ng} / \mathrm{ml}$ and free T3 level is 1.7 to $4.2 \mathrm{pg} / \mathrm{ml}$.

Subjects were classified into different clinical forms based on the obtained hormonal values

\section{Subclinical hypothyroidism}

High serum TSH level with normal fT4, fT3 level

\section{Overt hypothyroidism}

High serum TSH level with fT4 and fT3 less than normal range

Subclinical hyperthyroidism: Low serum TSH level with normal fT3, fT4 level

\section{Overt hyperthyroidism}

Low serum TSH level with fT3 and fT4 more than normal range

\section{Gestational diabetes $^{6-15}$}

For the diagnosis of gestational diabetes, oral glucose tolerance test (OGTT) was performed in several steps.

\section{Diagnostic test}

Study subject had taken about 8 ounces (237 milliliters) of a syrupy glucose solution containing 2.6 ounces (75 grams) of sugar by oral route. Two hours later, blood glucose level was measured.

\section{Two hours after drinking the glucose solution}

- A normal blood glucose level is lower than 140 $\mathrm{mg} / \mathrm{dL}(7.8 \mathrm{mmol} / \mathrm{L})$

- A blood glucose level between 140 and $199 \mathrm{mg} / \mathrm{dL}$ ( 7.8 and $11 \mathrm{mmol} / \mathrm{L}$ ) is considered impaired glucose tolerance, or prediabetes

- A blood glucose level of $200 \mathrm{mg} / \mathrm{dL}$ (11.1 mmol/L) or higher may indicate diabetes.

\section{Gestational hypertension}

It is defined as systolic blood pressure (SBP) $>140$ $\mathrm{mmHg}$ and diastolic blood pressure (DBP) $>90 \mathrm{mmHg}$.

\section{Classification}

- $\quad$ Mild (SBP 140-149 and DBP 90-99 mmHg)

- $\quad$ Moderate (SBP 150-159 and DBP 100-109 mmHg)

- Severe (SBP $\geq 160$ and $\mathrm{DBP} \geq 110 \mathrm{mmHg}$ ).

\section{RESULTS}

A total of 150 study subjects were recruited and 120 subjects completed entire study. Maternal demographic characteristics of study population are shown in Table 1. A total of $78.3 \%$ of study subjects were between the age group of 21-30 years. All subjects are fall within the normal BMI range and mean gestational age of 8.4 weeks.

Table 1: Baseline characteristics of maternal study population.

\begin{tabular}{|ll|}
\hline Characteristic & Number $($ Mean \pm SD $)$ \\
\hline $\mathbf{N}$ & $\mathbf{1 2 0}$ \\
\hline Age in years & $25.18 \pm 5.42$ \\
\hline$\leq 20, \mathrm{n}(\%)$ & $10(8.3)$ \\
\hline $21-25, \mathrm{n}(\%)$ & $46(38.3)$ \\
\hline $26-30, \mathrm{n}(\%)$ & $48(40.0)$ \\
\hline$>30, \mathrm{n}(\%)$ & $16(13.3)$ \\
\hline Range & $19-32$ \\
\hline Height in cm & $167.6 \pm 12.8$ \\
\hline Weight in kg & $53.8 \pm 7.3$ \\
\hline BMI & $19.0 \pm 2.8$ \\
\hline Gestational age in weeks & $8.4 \pm 2.9$ \\
\hline
\end{tabular}

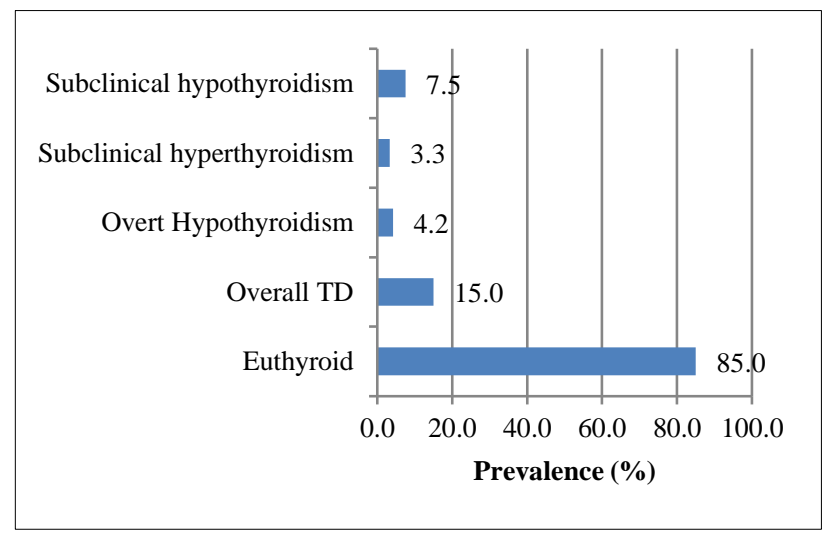

Figure 1: Prevalence of pregnancy induced thyroid disorders in study population.

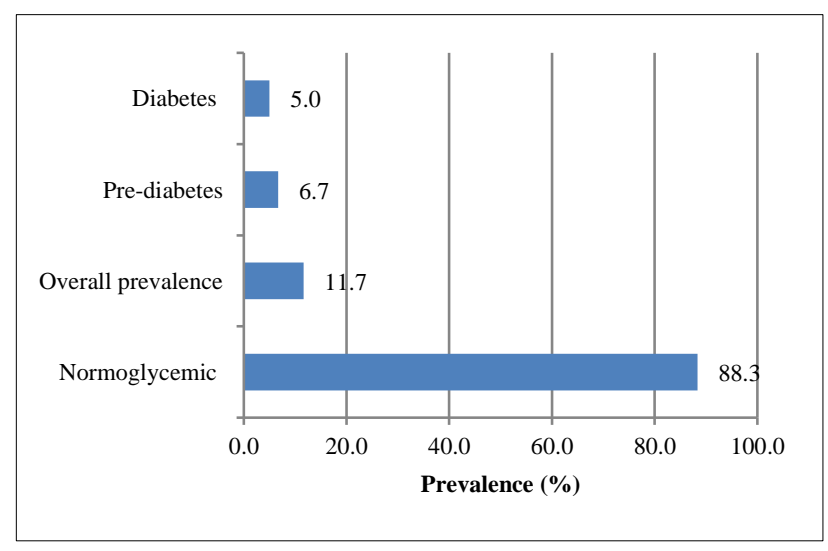

Figure 2: Prevalence of pregnancy induced diabetes in study population. 
Table 2: Serum thyroid hormone levels, blood glucose levels and blood pressure values of study population in the present study.

\begin{tabular}{|c|c|c|c|c|}
\hline \multicolumn{5}{|c|}{ Pregnancy induced thyroid dysfunction } \\
\hline Category & Euthyroid $(n=102)$ & $\begin{array}{l}\text { Overt } \\
\text { hypothyroidism } \\
(\mathbf{n = 0 5})\end{array}$ & $\begin{array}{l}\text { Subclinical } \\
\text { hyperthyroidism } \\
(\mathrm{n}=04)\end{array}$ & $\begin{array}{l}\text { Subclinical } \\
\text { hypothyroidism } \\
(\mathrm{n}=09)\end{array}$ \\
\hline TSH (mIU/L) & $1.61 \pm 0.38$ & $4.62 \pm 1.68$ & $0.03 \pm 0.00$ & $3.22 \pm 0.41$ \\
\hline $\mathrm{T} 3(\mathrm{pg} / \mathrm{ml})$ & $2.41 \pm 0.46$ & $0.72 \pm 0.06$ & $2.66 \pm 0.61$ & $2.86 \pm 0.38$ \\
\hline $\mathrm{T} 4$ (ng/ml) & $1.28 \pm 0.36$ & $0.31 \pm 0.16$ & $1.61 \pm 0.24$ & $1.12 \pm 0.28$ \\
\hline \multicolumn{5}{|c|}{ Pregnancy induced diabetes mellitus } \\
\hline & $\begin{array}{l}\text { Normoglycemic } \\
(n=106)\end{array}$ & $\begin{array}{l}\text { Pre-diabetes } \\
(\mathrm{n}=08)\end{array}$ & $\begin{array}{l}\text { Diabetes } \\
(\mathbf{n}=06)\end{array}$ & \\
\hline $\begin{array}{l}\text { Blood glucose levels } \\
\text { (mg/dL), After } 2 \text { hours }\end{array}$ & $126.12 \pm 11.28$ & $168.72 \pm 16.86$ & $230.68 \pm 17.48$ & \\
\hline \multicolumn{5}{|c|}{ Pregnancy induced hypertension } \\
\hline & $\begin{array}{l}\text { Normotensive } \\
(n=109)\end{array}$ & $\begin{array}{l}\text { Pre-hypertensive } \\
(\mathrm{n}=06)\end{array}$ & $\begin{array}{l}\text { Hypertensive } \\
(\mathrm{n}=05)\end{array}$ & \\
\hline SBP/DBP (mmHg) & $122.8 \pm 6.8 /$ & $134.2 \pm 5.4 /$ & $152.4 \pm 10.8 /$ & \\
\hline Position 1 & $84.2 \pm 4.8$ & $86.8 \pm 4.6$ & $96.6 \pm 6.4$ & \\
\hline SBP/DBP (mmHg) & $124.2 \pm 6.4 /$ & $134.8 \pm 5.6 /$ & $156.2 \pm 11.0 /$ & \\
\hline Position 2 & $86.4 \pm 5.0$ & $86.6 \pm 4.8$ & $98.6 \pm 6.8$ & \\
\hline
\end{tabular}

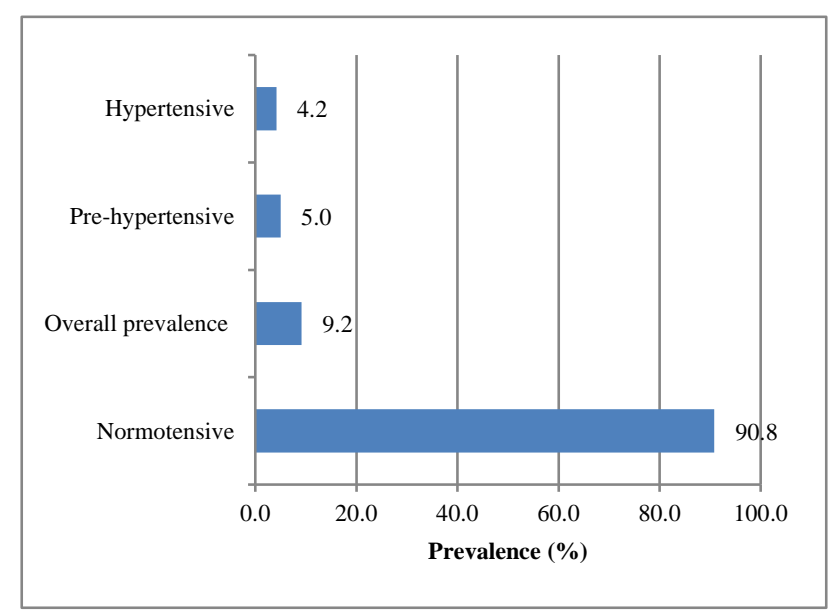

Figure 3: Prevalence of pregnancy induced hypertension in study population.

A total of $18(15.0 \%)$ subjects had pregnancy induced thyroid dysfunctions (Figure 1) in which overt hypothyroidism $(4.2 \%)$, subclinical hyperthyroidism $(3.3 \%)$ and subclinical hypothyroidism $(7.5 \%)$ was the highest. A total of $8(6.7 \%)$ subjects had pre-diabetes and $6(5.0 \%)$ subjects had diabetes in the study population. (Figure 2) Gestational diabetes subjects have mean blood glucose levels of $230.68 \pm 17.48 \mathrm{mg} / \mathrm{dL}$ with OGTT test (Table 2). A total of $5(4.2 \%)$ subjects had gestational hypertension and $6(5.0 \%)$ had pre-hypertension. (Figure 3) Hypertensive patients had SBP of $152.4 \pm 10.8$ and DBP of $96.6 \pm 6.4$; pre-hypertensive subjects had SBP of $134.2 \pm 5.48$ and DBP of $6.8 \pm 4.6$ respectively (Table 2 ).

\section{DISCUSSION}

The prevalence of thyroid disorders in the present study was $15.0 \%$. A study conducted by Sahu MT et al, studied on 633 pregnant women in second trimester and reported that prevalence of thyroid disorders was $12.7 \%$, slightly lower than the present study and these findings are comparable and inconsistent. ${ }^{16}$ Another study conducted by Pahwa $\mathrm{S}$ et al, studied on 100 women with first trimester of pregnancy and reported $10.0 \%$ of thyroid dysfunction prevalence ${ }^{1}$. The prevalence of subclinical hypothyroidism in the present study is $7.5 \%$. This finding is inconsistent with Sahu MT et al study which was showed $6.47 \%$ and Pahwa $\mathrm{S}$ et al, study showed $6.0 \%$. The present study finding was in contrast to Casey BM et al, study showed very less prevalence of $2.3 \% .^{17}$

The prevalence of overt hypothyroidism in present study is $4.2 \%$ which is almost inconsistent with Sahu MT et al, study reported $4.58 \%$ prevalence and our study finding is in contrast to Pahwa $\mathrm{S}$ et al, study had reported only 2.0\%.,16 The prevalence of subclinical and overt hyperthyroidism in our study is $3.3 \%$ and Nil respectively. Our findings are in contrast to Sahu MT et al, study which was reported $0.9 \%$ and $0.7 \%$ for subclinical and overt hyperthyroidism respectively. Another study conducted by Stagnaro Green A et al, and reported very low prevalence of subclinical hyperthyroidism $(0.5 \%) .{ }^{18}$ Sub clinical/ overt hypothyroid cases were treated with oral thyroxine sodium and sub clinical / overt hyperthyroid cases were treated with oral propylthiouracil. 
No specific recommendations are available for detection and screening of thyroid dysfunction in Indian pregnant population. Current Indian guidelines are recommending thyroid hormones level estimation only for high risk women with personal history of thyroid or other autoimmune disorders or with a family history of thyroid disorders. The present study had showed high prevalence rate of thyroid disorders especially subclinical and overt hypothyroidism among Indian pregnant women.

A total of $6.7 \%$ and $5.0 \%$ subjects had pre-diabetes and diabetes respectively in the present study. Single point OGTT was conducted and blood glucose levels were estimated after two hours $(230.68 \pm 17.48 \mathrm{mg} / \mathrm{dL})$. Kaiser Permanente health system studies accessed the incidence rates of GDM in pregnant women of multiple ethnicities. Both these studies had reported that people of Asian ethnicity has higher incidence. The overall incidence rate of GDM was $10 \%$, with higher rates in Asian (17\%) and Hispanic $(11 \%)$ women and lower rates in non-Hispanic white $(7 \%)$ and black (7\%) women. ${ }^{19,20}$ Bryson CL et al, conducted a study and reported that gestational diabetes was more common in each case group of $3.9 \%$ in eclamptics, $4.5 \%$ in severe preeclamptics, and $4.4 \%$ in both mild preeclamptics and those with gestational hypertension. $^{21}$ Gestational diabetes and pregnancyinduced hypertension are common, and their relation is not well understood. Hypertensive disorders are more with women have GDM and even high risk of diabetes mellitus after gestation period. ${ }^{22}$ Early diagnosis and treatment of GDM can reduce perinatal complications, but only a small fraction of pregnancies benefit. ${ }^{23}$ Dietary management, insulin, metformin and other newer oral anti-diabetic drugs are used to intensify treatment. ${ }^{24}$

A total of $4.2 \%$ and $5.0 \%$ subjects had gestational hypertension and pre-hypertension in the present study. Blood pressure was collected at two different internals of two different positions of pregnant women. Hypertensive patients had SBP of $152.4 \pm 10.8$ and DBP of 96.6 \pm 6.4 ; pre-hypertensive subjects had SBP of $134.2 \pm 5.48$ and DBP of $6.8 \pm 4.6$ respectively. Mehta B et al, conducted a study on pregnant women and reported $6.9 \%$ of prevalence. ${ }^{25}$ Sachdeva et al, conducted study in Gujarat, reported $15.0 \%$ of the incidence of pregnancy-induced hypertension among women of rural background. ${ }^{26}$ Several hospital-based studies in India have reported various prevalence rates which includes $7.49,5.38$, and $8.96 \%$ respectively. ${ }^{27}$

Non-drug management is recommended when SBP ranges between 140-149 $\mathrm{mmHg}$ and DBP between 90-99 $\mathrm{mmHg}$. Blood pressure thresholds for drug management in pregnancy vary between different healths organizations. According to 2013 ESH/ESC guidelines, antihypertensive treatment is recommended in pregnancy when blood pressure levels are $\geq 150 / 95 \mathrm{mmHg}$. Initiation of antihypertensive treatment at values $\geq 140 / 90$ $\mathrm{mmHg}$ is recommended with gestational hypertension. ${ }^{28-}$ 29

\section{CONCLUSION}

The present study reported the prevalence of thyroid dysfunction (15.0\%), gestational diabetes mellitus $(11.7 \%)$ and gestational hypertension $(9.2 \%)$ in the study population. These findings are slightly higher than normal prevalence's which are reported earlier by various authors. The present findings were suggested that early screening, diagnosis and treatment are warranted for the prevention of maternal and fetal complications in Indian population. The knowledge of risk factors for hypertensive disorders in pregnancy may give tracks for prevention in this population. Therefore, it is the need of hour to advice early screening strategy to find out pregnancy induced disorders.

\section{ACKNOWLEDGMENTS}

Authors would like to thank to the staff of Obstetrics and Gynaecology department and the management of maharajah's institute of medical sciences for providing facilities to carry out this research successfully.

Funding: No funding sources

Conflict of interest: None declared

Ethical approval: The study was approved by the Institutional Ethics Committee

\section{REFERENCES}

1. Pahwa S, Mangat S. Prevalence of thyroid disorders in pregnancy. Int $\mathrm{J}$ Reprod Contracept Obstet Gynecol. 2018;7:3493.

2. Van Raaij JM, Vermaat-Miedema SH, Schonk CM, Peek ME, Hautvast JG. Energy requirements of pregnancy in The Netherlands. Lancet Lond Engl. 1987;2:953-5.

3. Stagnaro-Green A, Abalovich M, Alexander E, Azizi F, Mestman J, Negro R, et al. Guidelines of the American Thyroid Association for the Diagnosis and Management of Thyroid Disease During Pregnancy and Postpartum. Thyroid. 2011;21:1081-125.

4. Ghassabian A, Bongers-Schokking JJ, de Rijke YB, van Mil N, Jaddoe VWV, de Muinck KeizerSchrama SMPF, et al. Maternal thyroid autoimmunity during pregnancy and the risk of attention deficit/hyperactivity problems in children: the generation R study. Thyroid. 2012;22:178-86.

5. Bhavadharini B, Mahalakshmi MM, Anjana RM, Maheswari K, Uma R, Deepa M, et al. Prevalence of gestational diabetes mellitus in urban and rural Tamil Nadu using IADPSG and WHO 1999 criteria (WINGS 6). Clin Diabetes Endocrinol. 2016;2. Available at: https://www.ncbi.nlm.nih.gov/pmc/articles/PMC547 $1800 /$.

6. Li KT, Naik S, Alexander M, Mathad JS. Screening and diagnosis of gestational diabetes in India: a systematic review and meta-analysis. Acta Diabetol. 2018;55:613-25. 
7. Nouhjah S, Shahbazian H, Shahbazian N, Jahanshahi A, Jahanfar S, Cheraghian B. Incidence and contributing factors of persistent hyperglycemia at 6 12 weeks postpartum in Iranian women with gestational diabetes: results from LAGA cohort study. J Diabetes Res. 2017:9786436.

8. Upadya M, Rao ST. Hypertensive disorders in pregnancy. Indian J Anaesth. 2018;62:675.

9. Fang R, Dawson A, Lohsoonthorn V, Williams MA. Risk factors of early and late onset preeclampsia among thai women. Asian Biomed Res Rev News. 2009;3:477-86.

10. Tebeu PM, Foumane P, Mbu R, Fosso G, Biyaga PT, Fomulu JN. Risk factors for hypertensive disorders in pregnancy: a report from the maroua regional hospital, cameroon. J Reprod Infertil. 2011;12:22734.

11. Amaral LM, Cunningham MW, Cornelius DC, LaMarca B. Preeclampsia: long-term consequences for vascular health. Vasc Health Risk Manag. 2015;11:403-15.

12. Matthys LA, Coppage KH, Lambers DS, Barton JR, Sibai BM. Delayed postpartum preeclampsia: an experience of 151 cases. Am J Obstet Gynecol. 2004;190:1464-6.

13. English FA, Kenny LC, McCarthy FP. Risk factors and effective management of preeclampsia. Integr Blood Press Control. 2015;8:7-12.

14. Bartsch E, Medcalf KE, Park AL, Ray JG. Clinical risk factors for pre-eclampsia determined in early pregnancy: systematic review and meta-analysis of large cohort studies. BMJ. 2016;353:i1753.

15. Dias S, Pheiffer C, Abrahams Y, Rheeder P, Adam S. Molecular biomarkers for gestational diabetes mellitus. Int J Mol Sci. 2018;19(10). Available at: https://www.ncbi.nlm.nih.gov/pmc/articles/PMC621 $3110 /$.

16. Sahu MT, Das V, Mittal S, Agarwal A, Sahu M. Overt and subclinical thyroid dysfunction among Indian pregnant women and its effect on maternal and fetal outcome. Arch Gynecol Obstet. 2010;281:215-20.

17. Casey BM, Dashe JS, Wells CE, McIntire DD, Byrd W, Leveno KJ, et al. Subclinical hypothyroidism and pregnancy outcomes. Obstet Gynecol. 2005;105:23945 .

18. Stagnaro-Green A, Pearce E. Thyroid disorders in pregnancy. Nat Rev Endocrinol. 2012;8:650-8.

19. Dabelea D, Snell-Bergeon JK, Hartsfield CL, Bischoff KJ, Hamman RF, McDuffie RS, et al. Increasing prevalence of gestational diabetes mellitus (GDM) over time and by birth cohort: Kaiser Permanente of Colorado GDM Screening Program. Diabetes Care. 2005;28:579-84.
20. Ferrara A, Kahn HS, Quesenberry CP, Riley C, Hedderson MM. An increase in the incidence of gestational diabetes mellitus: Northern California, 1991-2000. Obstet Gynecol. 2004;103:526-33.

21. Bryson CL, Ioannou GN, Rulyak SJ, Critchlow C. Association between gestational diabetes and pregnancy-induced hypertension. Am J Epidemiol. 2003; 158:1148-53.

22. Buchanan TA, Xiang AH, Page KA. Gestational diabetes mellitus: risks and management during and after pregnancy. Nat Rev Endocrinol. 2012;8:639-49.

23. Lowe WL, Scholtens DM, Lowe LP, Kuang A, Nodzenski $\mathrm{M}$, Talbot $\mathrm{O}$, et al. Association of gestational diabetes with maternal disorders of glucose metabolism and childhood adiposity. JAMA. 2018;320:1005-16.

24. Martis R, Hughes B, Rowan J, Crowther CA, Brown J. Oral anti-diabetic pharmacological therapies for the treatment of women with gestational diabetes. Cochrane Database Syst Rev. 2017;2017(1). Available at: https://www.ncbi.nlm.nih.gov/pmc/articles/PMC646 4763/.

25. Mehta B, Kumar V, Chawla S, Sachdeva S, Mahopatra D. Hypertension in pregnancy: a community-based study. Indian J Community Med Off Publ Indian Assoc Prev Soc Med. 2015;40:2738.

26. Sachdeva PD, Patel BG, Bhatt MV. A study of incidence and management of pregnancy induced hypertension in central Gujarat, India. Int J Univ Pharm Life Sci. 2011;61-70.

27. Nadkarni J, Bahl J, Parekh P. Perinatal outcome in pregnancy associated hypertension. Indian Pediatr. 2001;38:174-8.

28. Prakash J, Pandey LK, Singh AK, Kar B. Hypertension in pregnancy: hospital based study. J Assoc Physicians India. 2006;54:273-8.

29. Patel R, Baria H, Patel HR, Nayak S. A study on pregnancy induced hypertension and foetal outcome among patient with PIH at tertiary care hospital, Valsad. Int J Community Med Public Health. 2017;4:4277-81.

Cite this article as: Mummalaneni G, Narasingarao T, Myneni KK. Prevalence of pregnancy induced thyroid disorders, diabetes and hypertension in a tertiary care teaching hospital: an observational study. Int J Reprod Contracept Obstet Gynecol 2019;8:3201-6. 